\title{
INVESTIGATING ANTIMICROBIAL ACTIVITY OF SILVER NANOPARTICLES PRODUCED THROUGH GREEN SYNTHESIS USING LEAF EXTRACT OF COMMON GRAPE (VITIS VINIFERA)
}

\author{
ACAY, H. $^{1 *}-$ BARAN, M. F. ${ }^{2}-$ EREN, A. ${ }^{3}$ \\ ${ }^{I}$ Department of Nutrition and Dietetics, School of Health, Artuklu University, \\ 47200 Mardin, Turkey \\ ${ }^{2}$ Medical Laboratory Techniques, Vocational Higher School of Healthcare Studies, Artuklu \\ University, 47200 Mardin, Turkey \\ (e-mail: mfiratbaran@gmail.com) \\ ${ }^{3}$ Department of Crops and Animal Production, Kiziltepe Vocational Training High School, \\ Artuklu University, 47200 Mardin, Turkey \\ (e-mail: abdullaheren@artuklu.edu.tr) \\ *Corresponding author \\ e-mail: hilalacay@gmail.com \\ (Received $28^{\text {th }}$ Jan 2019; accepted $28^{\text {th }}$ Feb 2019)
}

\begin{abstract}
In this study, a direct approach to fabricating silver nanoparticles (AgNPs) via the leaf extract of common grape (Vitis vinifera) has been demonstrated. The produced particles were found with a maximum wavelength of $452.47 \mathrm{~nm}$, spherical shape and the crystal size of $18.53 \mathrm{~nm}$ through UV-Visible spectrophotometry, XRD (X-ray diffraction) and SEM (Scanning electron microscopy) characterization methods. Furthermore, the functional groups involved in the reduction were specified with FTIR (Fourier transform infrared spectroscopy), the elemental compounds were identified with EDX (Energy dispersive X-Ray spectroscopy) and the degradation points were determined with TGA-DTA (Thermal gravimetric analysis) methods. AgNPs were found to be effective against hospital pathogens, namely Gram-negative Escherichia coli ATCC 25922, Gram-positive Staphylococcus aureus ATCC 29213 and Candida albicans fungus at the concentrations of $0.314,0.078$ and $0.334 \mu \mathrm{g} \mathrm{mL}^{-1}$, respectively.
\end{abstract}

Keywords: green synthesis, metal nanoparticles, grape leaf extract, characterizations

\section{Introduction}

Nowadays, nanoparticles are widely used. These particles have found their use in different areas such as electronics, photography, material science, dye removal, cosmetics, biomedicine, bioremediation etc. (Saha et al., 2017; Swamy et al., 2015; Chaudhry et al., 2018). Green synthesis, which includes biological methods, is highly advantageous compared to physical and chemical methods due to it being environmentally friendly and not using toxic chemicals during any step (Sinsinwar et al., 2018; Ramkumar et al., 2017; Pantidos and Horsfall, 2014). Particles between the sizes of 1-100 $\mathrm{nm}$ are defined as nanoparticles. These nanoparticles can be obtained through biological, physical and chemical techniques (Ahmed et al., 2017). Since it is inexpensive and easy to obtain, the use of plants for the synthesis of nanoparticles is becoming increasingly common. Due to the strong antimicrobial activity of silver (Ag) against fungi, viruses, and bacteria, AgNPs have been a subject of study by researchers from many different fields in recent years, and it has been stated that AgNPs have antiinflammatory properties in addition to their antimicrobial properties (Shah et al., 2017). Silver nanoparticle synthesis and phytochemicals in plant leaf extracts create AgNPs by 
reducing $\mathrm{Ag}^{+}$ions present in the medium to $\mathrm{Ag}^{0}$ and also provide stability (Geethalakshmi and Sarada, 2010; Prakash et al., 2013; Ahmed et al., 2018). Green synthesis is an important phenomenon that must be taken into consideration, especially since it supports the use of non-toxic chemicals, and environmentally friendly, renewable materials (Kaushal et al., 2016). Plant-based green synthesis generally uses different parts of plants (leaves, roots, seeds and fruits) (Majeed et al., 2018).

In this research, the green synthesis, which is an environmentally friendly, easy and simple method, was used to synthesize AgNPs from the leaf extract of the common grape (Vitis vinifera) and its antimicrobial effect on microorganisms was investigated.

\section{Materials and methods}

\section{Preparation of Vitis vinifera extract and silver nitrate $\left(\mathrm{AgNO}_{3}\right)$ solution}

Collected grape leaves from Mardin region in Turkey were initially washed with tap water, then washed with distilled water and finally dried under room conditions. After the drying process, the dried leaves were grounded, then boiled with distilled water and filtered at room temperature using coarse filter paper followed by Whatman 1 filter paper and the extract was obtained for the synthesis of AgNPs. Afterwards, $1 \mathrm{mM}$ solution was prepared using solid $\mathrm{AgNO}_{3}$ (purity 99.8\%, Sigma-Aldrich).

\section{Synthesis and characterization}

The leaf extract and the $\mathrm{AgNO}_{3}$ solution were mixed in a ratio of 1: 4, and after the color change in a few minutes, subsequently the formation and presence of silver nanoparticles were observed with Perkin Elmer one UV Visible spectrophotometer. After centrifugation with OHAUS FC 5706 at $10.000 \mathrm{rpm}$ for $5 \mathrm{~min}$, the resulting nanoparticles were dried. Then the RadB-DMAX II computer controlled X-ray diffractometer for XRD, the scanning electron microscope EVO 40 LEQ for SEMEDAX, the Perkin Elmer Spectrum One for FTIR, and the Shimadzu TGA-50 for TGADTA were used to determine the characterization of the synthesized AgNPs.

\section{Determining antimicrobial effects of silver nanoparticles}

The antimicrobial effects of the obtained AgNPs were examined on pathogenic microorganisms, Gram-negative Escherichia coli ATCC 25922, Gram-positive Staphylococcus aureus ATCC 29213 bacteria and Candida albicans yeast. The minimum inhibitory concentration (MIC) was determined by the micro dilution method. In the experiments, Mueller-Hinton medium, the solutions including a certain amount of microorganism, which were prepared according to $0.5 \mathrm{McFarland}$ standard, and appropriate concentrations of the AgNP solution were added to 96-well microplates and wells were incubated at $37^{\circ} \mathrm{C}$ overnight (El-Batal et al., 2018; Vishwasrao et al., 2018; Dhand et al., 2016). The next day, the MIC was determined by the well in which the reproduction ended. To compare the effects of AgNPs, commercially available vancomycin, colistin and fluconazole antibiotics and a $1 \mathrm{mM} \mathrm{AgNO}$ aqueous solution were used on S. aureus, E. coli, and C. albicans. 


\section{Results and discussion}

After a few minutes of mixing the grape plant and the $\mathrm{AgNO}_{3}$ solution, a dark coffee color change was observed indicating the formation of AgNPs by vibrations on the plasma surface (Alruqi et al., 2018). Data with the maximum absorbance of $452.47 \mathrm{~nm}$ were obtained (Fig. 1). The maximum absorbance in the synthesis with green tea and turmeric extracts was found to be $450 \mathrm{~nm}$ (Selvan et al., 2018). In another study conducted with the green synthesis, it was stated that the maximum absorbance was at $460 \mathrm{~nm}$ (Begum et al., 2009).
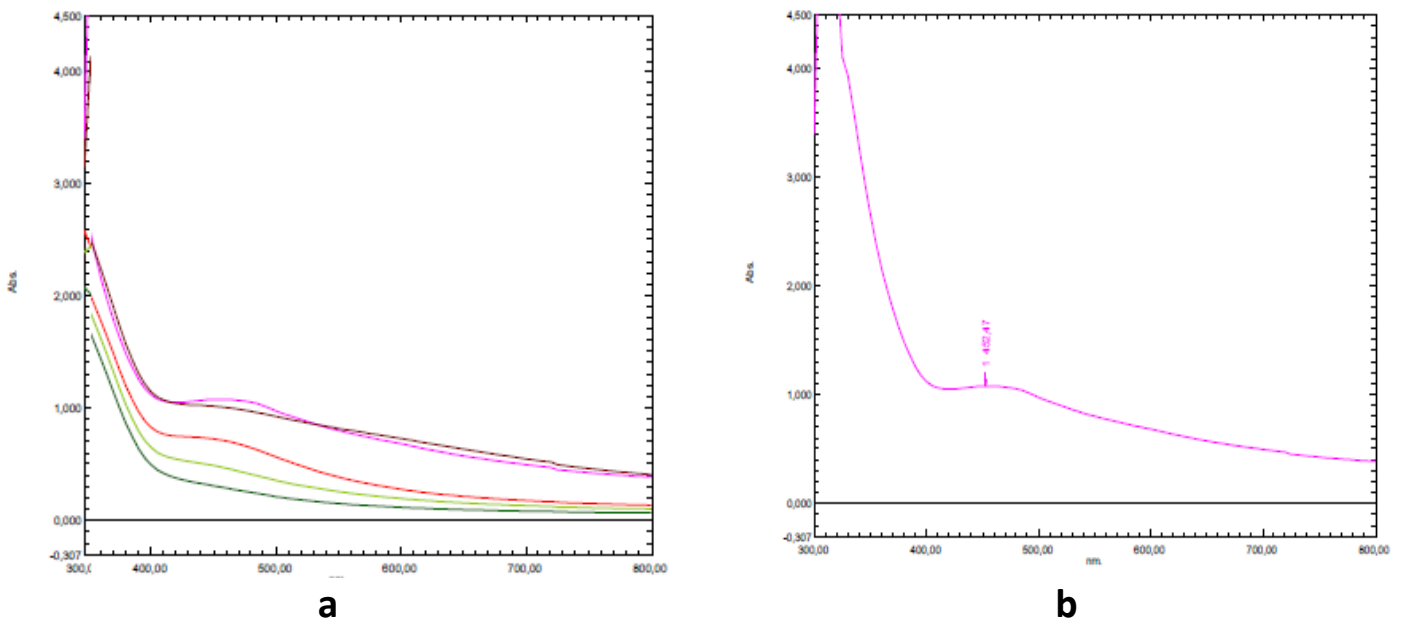

Figure 1. a. Time-dependent formation of AgNPs in UV spectroscopy. $\boldsymbol{b}$. Maximum absorbance of synthesized AgNP in UV spectrophotometry

Functional groups involved in the reduction were evaluated via FTIR analysis. It was thought that the shifts at 3332, 2127 and $1635 \mathrm{~cm}^{-1}$ were caused by the active role of $\mathrm{OH},-\mathrm{CN}$ and $\mathrm{C}=\mathrm{O}$ groups in the reduction (Fig. 2). Similar groups were evaluated in the nanoparticle synthesis study with Matricaria chamomilla extract (Dadashpour et al., 2018). Other study results also support these findings (Selvakumar et al., 2018).
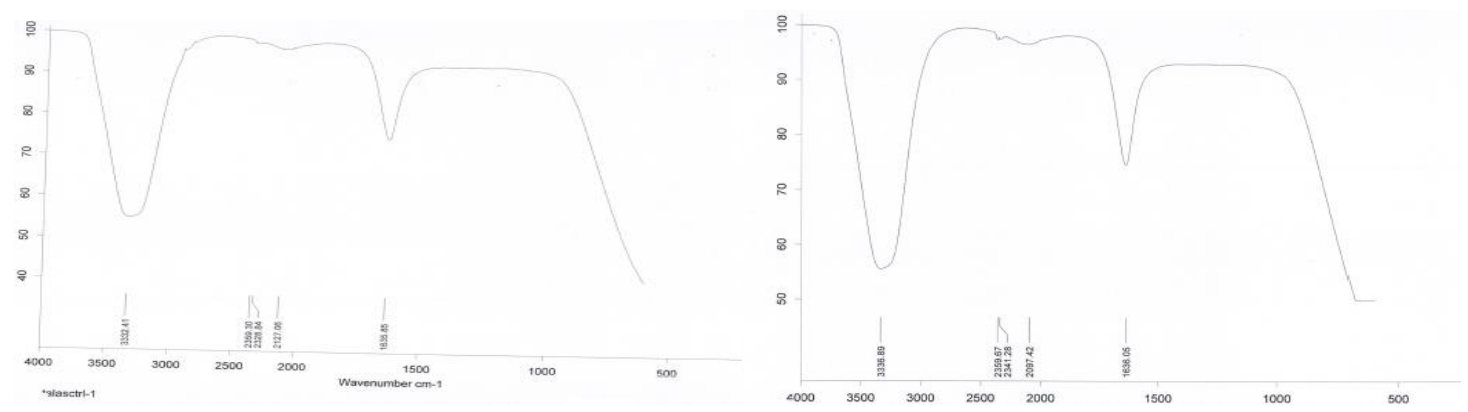

Figure 2. $U V$-vis spectrum of plant extract and $U V$-vis spectrum of synthesized AgNPs

The crystal structure of the obtained AgNPs particles was found by the $2 \theta$ values of $38.52^{\circ}, 44.71^{\circ}, 64.85^{\circ}$ and $77.72^{\circ}$ from the peaks which were located at (111), (200), (220) and (311) (Fig. 3). In the study with Melissa officinali, the peaks at (111), (200), (220) and (311) were associated with AgNPs (de Jesús Ruíz-Baltazar et al., 2017). The 
orientation at (111), (200), (220) and (311) were also connected to AgNPs in the nanoparticle synthesis research of Coffea arabica extract (Dhand et al., 2016).

The crystal dimensions of AgNPs were determined as $18.53 \mathrm{~nm}$ using DebyeScherrer equation $[D=K \lambda /(\beta \cos S c h)]$.

In other studies on the synthesis of AgNPs, the crystal dimensions of the nanoparticles were calculated using Debye-Scherrer equation (Pugazhendhi et al., 2018; Rajesh et al., 2018; Jogaiah et al., 2017).

It was seen that AgNPs were spherical in SEM images, and according to EDAX, there were peaks of Ag metal in the elemental composition (Fig. 4). It was reported that the AgNPs obtained in a study with Physalis angulata extract also have a spherical shape (Nishanthi et al., 2018). Many researchers have reported having synthesized AgNPs in spherical shapes (Premkumar et al., 2018; Alam et al., 2018; Ibrahim et al., 2016).

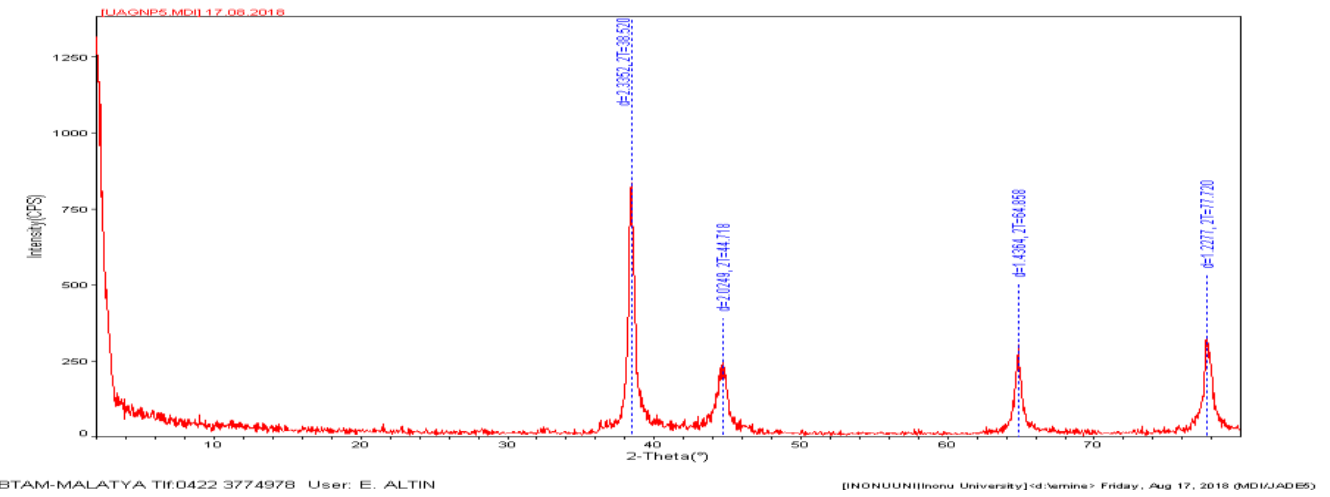

Figure 3. $X$-ray diffraction (XRD) analysis
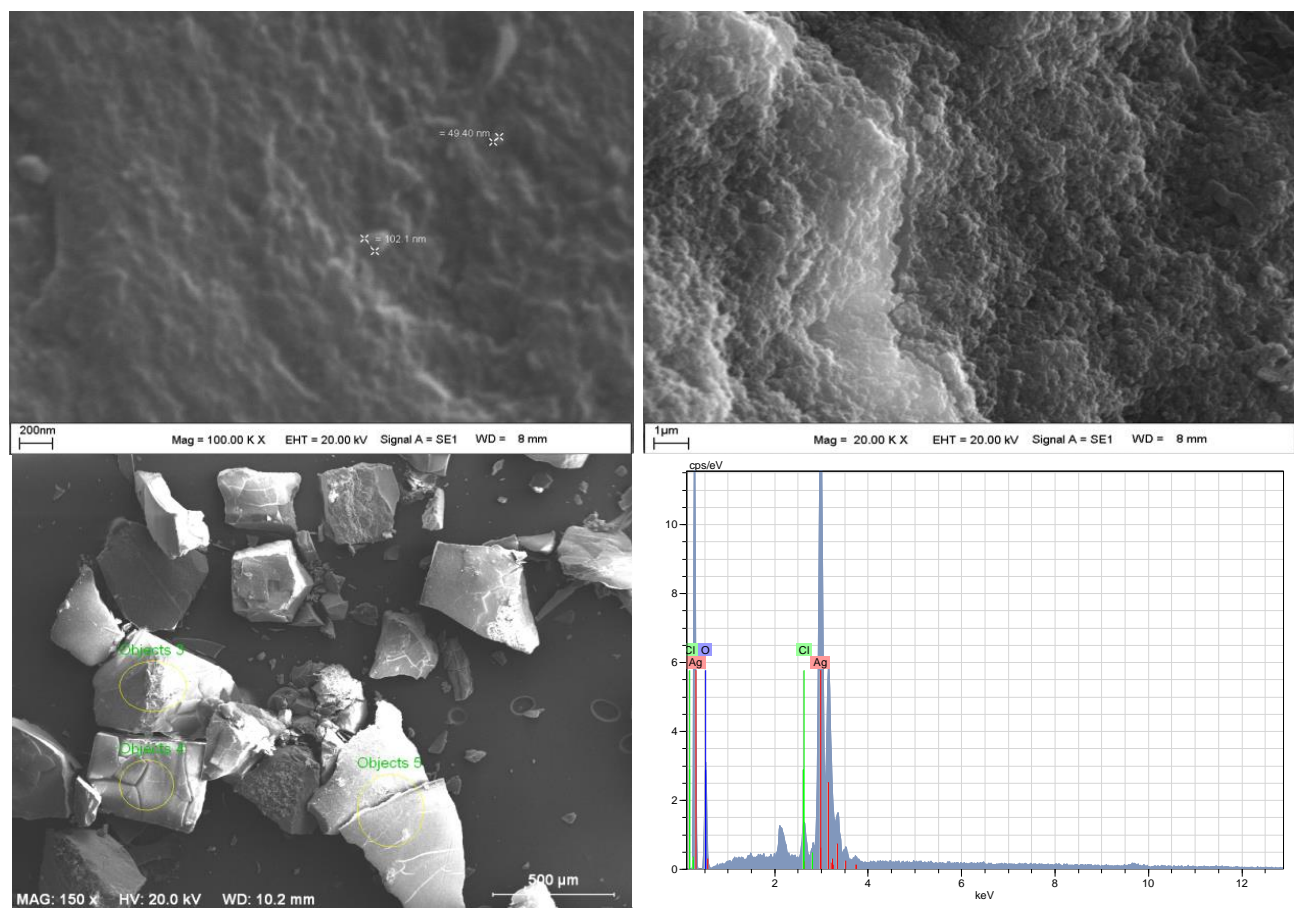

Figure 4. SEM-EDAX results of AgNPS 
The TGA and DTA analyses of the AgNPs were evaluated between $30-900{ }^{\circ} \mathrm{C}$ with a heating rate of $10{ }^{\circ} \mathrm{C} \mathrm{min}-1$ and a flow rate of $20 \mathrm{~mL} \mathrm{~min}^{-1}$ in $\mathrm{N}_{2}(\mathrm{~g})$ atmosphere. The TGA curve indicates the mass loss of the nanoparticles versus the temperature, and the DTA curve shows the highest decomposition temperature at all levels of the degradation (Baran et al., 2018).

The loss of mass at $30-201{ }^{\circ} \mathrm{C}$ was caused by moisture, while the loss of mass at 201$515{ }^{\circ} \mathrm{C}$ was due to phytochemicals in the plant extract and the green synthesized AgNPs were gradually degraded between $515-810{ }^{\circ} \mathrm{C}$ (Fig. 5).
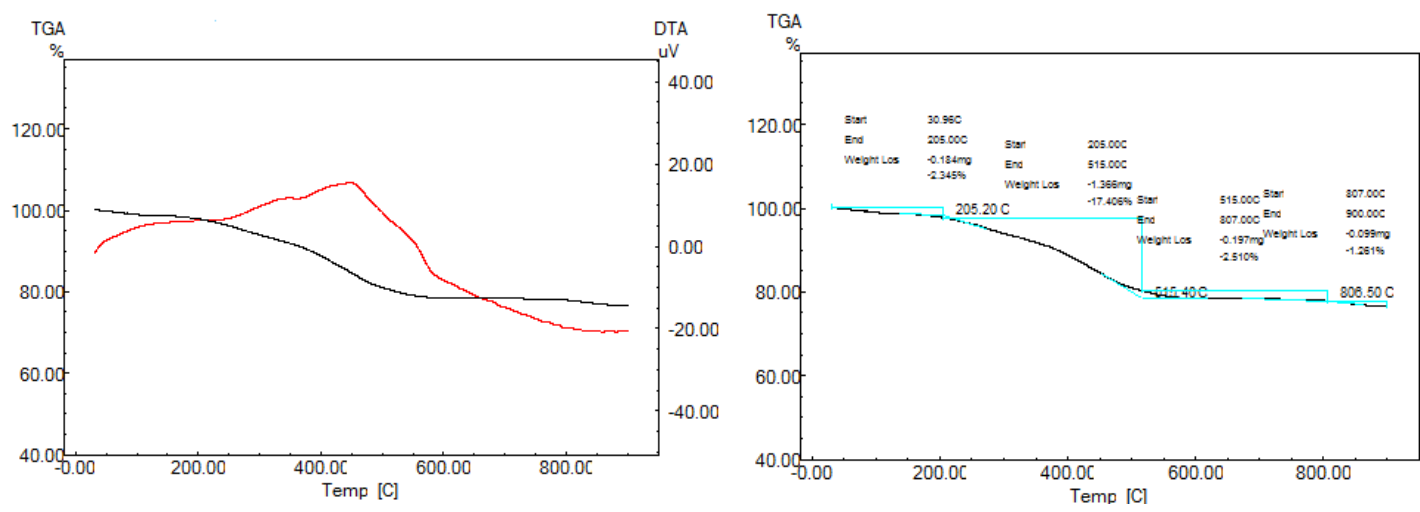

Figure 5. TGA-DTA results of synthesized AgNPs

The minimum inhibitory concentrations (MIC) of AgNPs on Gram-negative Escherichia coli ATCC 25922, Gram-positive Staphylococcus aureus ATCC 29213 bacteria and Candida albicans microorganisms were found to be $0.078,0.314$ and $0.331 \mu \mathrm{g} \mathrm{mL} \mathrm{m}^{-1}$, respectively (Table 1). In the green synthesis and characterization of AgNPs from Abelia grandiflora, MIC values of Gram-negative and Gram-positive bacteria were found to be $3.12 \mu \mathrm{g} \mathrm{mL}^{-1}$ for $E$. coli and $12.5 \mu \mathrm{g} \mathrm{mL} \mathrm{m}^{-1}$ for $S$. aureus (Sharma et al., 2014).

Table 1. MIC values of synthesized silver nanoparticles (AgNPs), silver nitrate, vancomycin, fluconazole and colistin antibiotics on S. aureus, C. albicans and E. coli

\begin{tabular}{c|c|c|c}
\hline Organism & $\begin{array}{c}\text { AgNP } \\
\left(\mu \mathbf{g} \mathbf{~ m L}^{-1}\right)\end{array}$ & $\begin{array}{c}\text { Antibiotic } \\
\left(\boldsymbol{\mu g} \mathbf{~ m L}^{-1}\right)\end{array}$ & $\begin{array}{c}\text { Silver nitrate } \\
\left(\boldsymbol{\mu} \mathbf{~ m L}^{-1}\right)\end{array}$ \\
\hline S. Aureus ATCC 29213 & 0.314 & 0.50 & 0.50 \\
E. coli ATCC 25922 & 0.078 & 0.12 & 1.00 \\
C. albicans & 0.331 & 0.06 & 0.50 \\
\hline
\end{tabular}

\section{Conclusion}

In this research, synthesis of AgNPs was performed using the common grape (Vitis vinifera) leaf extract. It was determined that AgNPs had spherical shapes with sizes around $75 \mathrm{~nm}$ according to the data obtained from the SEM images, and also had a crystal size of $18.53 \mathrm{~nm}$ according to XRD results. FTIR results showed that the functional groups involved in the reduction were $-\mathrm{OH},-\mathrm{CN}$ and $\mathrm{C}=\mathrm{O}$. The antimicrobial effect of nanoparticles was determined to be significant on E. coli ATCC 25922 and $S$. aureus ATCC 29213 strains. In the light of these results, the usage of the nanoparticles 
obtained by an environmentally friendly synthesis can be improved for the medical industry due to their biocompatibility as antimicrobial agents. With their antimicrobial effect, AgNPs are thought to be effective in bioremediation of wastewater due to their rapid and efficient synthesis, as well as their being used in many areas such as shelf life extension, cosmetics, and others.

\section{REFERENCES}

[1] Ahmed, S., Chaudhry, S. A., Ikram, S. (2017): A review on biogenic synthesis of ZnO nanoparticles using plant extracts and microbes: A prospect towards green chemistry. Journal of Photochemistry and Photobiology B: Biology 166: 272-284.

[2] Ahmed, S. W., Anwar, H., Siddiqui, A., Shah, M. R., Ahmed, A., Ali, S. A. (2018): Synthesis and chemosensing of nitrofurazone using olive oil based silver nanoparticles (O-AgNPs). - Sensors and Actuators B: Chemical 256: 429-439.

[3] Alam, M. T., Rauf, M. A., Siddiqui, G. A., Owais, M., Naeem, A. (2018): Green synthesis of silver nanoparticles, its characterization, and chaperone-like activity in the aggregation inhibition of $\alpha$-chymotrypsinogen A. - International Journal of Biological Macromolecules 120: 2381-2389.

[4] Alruqi, S. S., Al-Thabaiti, S. A., Malik, M. A., Khan, Z. (2018): Role of surfactants: One step facile synthesis of hetero structured Ag-Ni alloy by seed less approach. - Colloids and Surfaces A: Physicochemical and Engineering Aspects 540: 36-47.

[5] Baran, M. F., Duz M, Z., Uzan, S., Dolak, brahim, Celik K, S., Kilinc, E. (2018): Removal of $\mathrm{Hg}$ (II) from Aqueous Solution by Bacillus subtilis ATCC 6051 (B1). Journal of Bioprocessing \& Biotechniques 08(04): 1-7.

[6] Begum, N. A., Mondal, S., Basu, S., Laskar, R. A., Mandal, D. (2009): Biogenic synthesis of $\mathrm{Au}$ and $\mathrm{Ag}$ nanoparticles using aqueous solutions of black tea leaf extracts. Colloids and Surfaces B: Biointerfaces 71(1): 113-118.

[7] Chaudhry, N., Dwivedi, S., Chaudhry, V., Singh, A., Saquib, Q., Azam, A., Musarrat, J. (2018): Bio-inspired nanomaterials in agriculture and food: Current status, foreseen applications and challenges. - Microbial Pathogenesis 123: 196-200.

[8] Dadashpour, M., Firouzi-Amandi, A., Pourhassan-Moghaddam, M., Maleki, M. J., Soozangar, N., Jeddi, F. et al. (2018): Biomimetic synthesis of silver nanoparticles using Matricaria chamomilla extract and their potential anticancer activity against human lung cancer cells. - Materials Science and Engineering C 92: 902-912.

[9] de Jesús Ruíz-Baltazar, Á., Reyes-López, S. Y., Larrañaga, D., Estévez, M., Pérez, R. (2017): Green synthesis of silver nanoparticles using a Melissa officinalis leaf extract with antibacterial properties. - Results in Physics 7: 2639-2643.

[10] Dhand, V., Soumya, L., Bharadwaj, S., Chakra, S., Bhatt, D., Sreedhar, B. (2016): Green synthesis of silver nanoparticles using Coffea arabica seed extract and its antibacterial activity. - Materials Science and Engineering C 58: 36-43.

[11] El-Batal, A. I., Al-Hazmi, N. E., Mosallam, F. M., El-Sayyad, G. S. (2018): Biogenic synthesis of copper nanoparticles by natural polysaccharides and Pleurotus ostreatus fermented fenugreek using gamma rays with antioxidant and antimicrobial potential towards some wound pathogens. - Microbial Pathogenesis 118: 159-169.

[12] Geethalakshmi, R., Sarada, D. V. L. (2010): Synthesis of plant-mediated silver nanoparticles using Trianthema decandra extract and evaluation of their anti microbial activities. - International Journal of Engineering Science and Technology 2(5): 970-975.

[13] Ibrahim, N. A., Eid, B. M., Abdel-Aziz, M. S. (2016): Green synthesis of AuNPs for ecofriendly functionalization of cellulosic substrates. - Applied Surface Science 389: 118125. 
[14] Jogaiah, S., Kurjogi, M., Abdelrahman, M., Hanumanthappa, N., Tran, L. S. P. (2017): Ganoderma applanatum-mediated green synthesis of silver nanoparticles: Structural characterization, and in vitro and in vivo biomedical and agrochemical properties. Arabian Journal of Chemistry. https://doi.org/10.1016/j.arabjc.2017.12.002.

[15] Kaushal, J., Bhatti, J., Kumar, P. (2016): Green synthesis and physico-chemical study of silver nanoparticles extracted from a natural source Luffa acutangula. - Journal of Molecular Liquids 224: 991-998.

[16] Majeed, A., Ullah, W., Anwar, A. W., Shuaib, A., Ilyas, U., Khalid, P. et al. (2018): Costeffective biosynthesis of silver nanoparticles using different organs of plants and their antimicrobial applications: A review. - Materials Technology 33(5): 313-320.

[17] Nishanthi, R., Malathi, S., Paul, S. J., Palani, P. (2018): Green synthesis and characterization of bioinspired silver, gold and platinum nanoparticles and evaluation of their synergistic antibacterial activity after combining with different classes of antibiotics. - Materials Science and Engineering C 96: 693-707.

[18] Pantidos, N., Horsfall, L. E. (2014): Biological synthesis of metallic nanoparticles by bacteria, fungi and plants. - Journal of Nanomedicine \& Nanotechnology 5(5): 1.

[19] Prakash, P., Gnanaprakasam, P., Emmanuel, R., Arokiyaraj, S., Saravanan, M. (2013): Green synthesis of silver nanoparticles from leaf extract of Mimusops elengi, Linn. for enhanced antibacterial activity against multi drug resistant clinical isolates. - Colloids and Surfaces B: Biointerfaces 108: 255-259.

[20] Premkumar, J., Sudhakar, T., Dhakal, A., Shrestha, J. B., Krishnakumar, S., Balashanmugam, P. (2018): Synthesis of silver nanoparticles (AgNPs) from cinnamon against bacterial pathogens. - Biocatalysis and Agricultural Biotechnology15: 311-316.

[21] Pugazhendhi, S., Palanisamy, P. K., Jayavel, R. (2018): Synthesis of highly stable silver nanoparticles through a novel green method using Mirabillis jalapa for antibacterial, nonlinear optical applications. - Optical Materials 79: 457-463.

[22] Rajesh, K. M., Ajitha, B., Reddy, Y. A. K., Suneetha, Y., Reddy, P. S. (2018): Assisted green synthesis of copper nanoparticles using Syzygium aromaticum bud extract: Physical, optical and antimicrobial properties. - Optik - International Journal for Light and Electron Optics 154: 593-600.

[23] Ramkumar, V. S., Pugazhendhi, A., Gopalakrishnan, K., Sivagurunathan, P., Saratale, G. D., Dung, T. N. B., Kannapiran, E. (2017): Biofabrication and characterization of silver nanoparticles using aqueous extract of seaweed Enteromorpha compressa and its biomedical properties. - Biotechnology Reports 14: 1-7.

[24] Saha, J., Begum, A., Mukherjee, A., Kumar, S. (2017): A novel green synthesis of silver nanoparticles and their catalytic action in reduction of Methylene Blue dye. - Sustainable Environment Research 27(5): 245-250.

[25] Selvakumar, P., Sithara, R., Viveka, K., Sivashanmugam, P. (2018): Green synthesis of silver nanoparticles using leaf extract of Acalypha hispida and its application in blood compatibility. - Journal of Photochemistry and Photobiology B: Biology 182: 52-61.

[26] Selvan, D. A., Mahendiran, D., Kumar, R. S., Rahiman, A. K. (2018): Garlic, green tea and turmeric extracts-mediated green synthesis of silver nanoparticles: Phytochemical, antioxidant and in vitro cytotoxicity studies. - Journal of Photochemistry and Photobiology B: Biology 180: 243-252.

[27] Shah, M., Poinern, G. E. J., Fawcett, D. (2017): Biosynthesis of silver nanoparticles using indigenous Xanthorrhoea glauca leaf extract and their antibacterial activity against Escherichia coli and Staphylococcus epidermis. - International Journal of Research in Medical Sciences 4(7): 2886-2892.

[28] Sharma, G., Jasuja, N. D., Rajgovind, R., Singhal, P., Joshi, S. C. (2014): Synthesis, characterization and antimicrobial activity of Abelia grandiflora assisted AgNPs. Journal of Microbial and Biochemical Technology 6(5): 274-278.

[29] Sinsinwar, S., Sarkar, M. K., Suriya, K. R., Nithyanand, P., Vadivel, V. (2018): Use of agricultural waste (coconut shell) for the synthesis of silver nanoparticles and evaluation 
of their antibacterial activity against selected human pathogens. - Microbial Pathogenesis 124: 30-37.

[30] Swamy, M. K., Akhtar, M. S., Mohanty, S. K., Sinniah, U. R. (2015): Synthesis and characterization of silver nanoparticles using fruit extract of Momordica cymbalaria and assessment of their in vitro antimicrobial, antioxidant and cytotoxicity activities. Spectrochimica Acta Part A: Molecular and Biomolecular Spectroscopy 151: 939-944.

[31] Vishwasrao, C., Momin, B., Ananthanarayan, L. (2018): Green synthesis of silver nanoparticles using sapota fruit waste and evaluation of their antimicrobial activity. Waste and Biomass Valorization. DOI: 10.1007/s12649-018-0230-0. 